Article

\title{
Cross-Resistance: A Consequence of Bi-partite Host-Parasite Coevolution
}

\author{
Tilottama Biswas ${ }^{1,2, *(\mathbb{D}) \text {, Gerrit Joop }}{ }^{1}$ and Charlotte Rafaluk-Mohr ${ }^{1,3, * \text { (D) }}$ \\ 1 Institute of Insect Biotechnology, Justus-Liebig University Giessen, Heinrich Buff Ring 29-32, \\ 35392 Giessen, Germany; g.joop@gmx.de \\ 2 Institute of Animal Ecology, Leuphana University of Lüneburg, 21335 Lüneburg, Germany \\ 3 Department of Zoology, University of Oxford, South Parks Road, Oxford OX1 3PS, UK \\ * Correspondence: Biswas@leuphana.de (T.B.); charlotte.rafaluk@zoo.ox.ac.uk (C.R.-M.); \\ Tel.: +49-4131-677-2902; Fax: +49-4131-677-2808
}

Received: 28 November 2017; Accepted: 19 February 2018; Published: 26 February 2018

\begin{abstract}
Host-parasite coevolution can influence interactions of the host and parasite with the wider ecological community. One way that this may manifest is in cross-resistance towards other parasites, which has been observed to occur in some host-parasite evolution experiments. In this paper, we test for cross-resistance towards Bacillus thuringiensis and Pseudomonas entomophila in the red flour beetle Tribolium castaneum, which was previously allowed to coevolve with the generalist entomopathogenic fungus Beauveria bassiana. We combine survival and gene expression assays upon infection to test for cross-resistance and underlying mechanisms. We show that larvae of T. castaneum that evolved with $B$. bassiana under coevolutionary conditions were positively cross-resistant to the bacterium $B$. thuringiensis, but not P. entomophila. Positive cross-resistance was mirrored at the gene expression level with markers that were representative of the oral route of infection being upregulated upon B. bassiana exposure. We find that positive cross-resistance towards B. thuringiensis evolved in T. castaneum as a consequence of its coevolutionary interactions with $B$. bassiana. This cross-resistance appears to be a consequence of resistance to oral toxicity. The fact that coevolution with B. bassiana results in resistance to $B$. thuringiensis, but not P. entomophila implies that $B$. thuringiensis and B. bassiana may share mechanisms of infection or toxicity not shared by P. entomophila. This supports previous suggestions that $B$. bassiana may possess Cry-like toxins, similar to those found in B. thuringiensis, which allow it to infect orally.
\end{abstract}

Keywords: route of infection; RT-qPCR; Tribolium castaneum; Beauveria bassiana; Bacillus thuringiensis; Pseudomonas entomophila; multiple parasites

\section{Introduction}

In nature, hosts are likely to exist within a complex community and interact with multiple parasites [1-3]. Close bipartite species interactions established over evolutionary time are likely to impact other ecological interactions within the community [4-7], including those with other parasite species [8]. In spite of this, to date, few experimental studies investigate the consequence of bipartite host-parasite interactions on host interactions with other parasites [9-13]. Many host-parasite coevolution experiments attempt to understand the dynamics [14,15], adaptations [16-18], and underlying genetic mechanisms [16,19-21] of host responses in the context of the parasite it coevolved with. Such evolutionary interactions can impact host traits important in the wider context of its environment [22]. For example, larvae of Drosophila melanogaster evolved with the parasitoid Asobara tabida displayed reduced competitive ability under high competition [22]. However, broad-scale effects of coevolution on hosts' interactions with a wider community of parasites as a consequence of host-parasite coevolution are yet to be investigated. Cross-resistance is one such broad-scale effect [23]. 
Cross-resistance is a host defence mechanism that develops as a response to parasite infection, whereby host evolutionary interactions with one parasite (A) leads to either host resistance, tolerance, or hyper-susceptibility to another parasite (B or C) [23]. When evolutionary interaction with a parasite (A) results in the host being resistant to previously un-encountered parasites (B) it is termed as positive cross-resistance [23]. For example, Martins et al. [10] reported that experimental evolution of the fruit fly Drosophila melanogaster with the bacterium Pseudomonas entomophila (A) results in the flies being resistant to P. putida (B). Alternatively, since mounting an immune response and developing resistance can come with associated life-history costs [24,25], evolutionary interaction with a parasite may result in the host being hyper-susceptible to a new and previously un-encountered parasite (C), leading to negative cross-resistance [23]. Martins et al., [10] also observed that the evolved flies were more susceptible to infection by viruses (flock house virus (FHV) and Drosophila C virus (DCV)) as compared to their control counterparts. It was proposed that the higher survival of flies evolved to P. entomophila upon infection with P. putida comes at a cost which is manifested in the form of hyper-susceptibility to viral infections (C) [10]. In another study where D. melanogaster was allowed to adapt to DCV for 20 generations, a genome-wide analysis of the evolved flies revealed that their cross-resistance to the cricket paralysis virus (CrPV) and the FHV are mediated by the gene Pastrel and two other loci, namely Ubc-E2H and CG8492 [13]. The authors further confirmed this observation by knocking out these candidates in flies using RNAi, which resulted in significantly higher mortality when exposed to the aforementioned viruses [13]. However, mechanisms of cross-resistance are poorly understood and rarely studied in other host-parasite systems. Host evolution with endosymbiontic bacteria can also influence interactions with potential parasites. These live within the body of the insect host and have also been observed to confer protective benefits against parasites. The vertically transmitted falcultative endosymbiont Regiella insecticola increases host resistant to fungal parasites Pandora aphididis [26] and Zoophthora occidentalis [27] in the pea aphid Acryrthosiphon pisum. The male-killing endosymbionts of D. melanogaster, Spiroplasma, and Wolbachia, protect flies by reducing the survival of parasitoid wasps [28].

Cross-resistance can occur at the evolutionary (manifested across generation) or ecological (manifested within generation) level [23]. At the evolutionary level, it has been proposed that cross-resistance to one parasite (A) is connected with resistance to a different parasite (B, C), by means of shared defence mechanism [13]. This is shown by D. melanogaster evolved to DCV when exposed to CrPV and FHV, as discussed before [13]. At the ecological level, cross-resistance is the result of the activation of immune defence caused by the previous exposure to a different parasite (A) [23]. For instance, within the same generation, prior exposure of the mosquito Anopheles gambiae to the microsporidian parasite Vavria culicis (A) results in the mosquitoes being more resistant to Plasmodium berghei (B), when compared to control mosquitoes, due to an enhanced melanisation response [1]. Within the context of this paper we refer to the evolutionary definition of cross-resistance.

To date, only a handful of studies have tested whether, under simple experimental evolution conditions, host resistance leads to general cross-resistance effects upon exposure to different parasites $[9,11,23,29]$. Fellowes et al. [9] showed that populations of $D$. melanogaster experimentally evolved with the parasitoid wasp Leptopilina boulardi demonstrated positive cross-resistance towards L. heterotoma, but no difference in resistance towards A. tabida. Kraaijeveld et al. [23], reported that D. melanogaster experimentally evolved to $A$. tabida exhibited no change in resistance towards either the fungus Beauveria bassiana or microsporidian Tubulinosema kingi. Bentz, and colleagues [29] reported no difference in D. melanogaster's resistance towards Drosophila sigma virus after experimental evolution with Bacillus cereus. Similarly, the greater wax moth Galleria mellonela evolved with the fungus Beauveria bassiana, displayed no difference in resistance to the fungus Metarhizium anisopliae [11]. It remains unclear why hosts are cross-resistant to some parasites and not others.

The few studies reporting cross-resistance have tried to understand the underlying mechanisms at play, such as specificity of route of infection [10] or the genetic basis of resistance [13]. In cases that have reported positive cross-resistance, the first (A) and the subsequent parasite (B) the host was 
exposed to were closely related $[9,10,13]$, resulting in the host employing similar immune mechanism against both. Furthermore, in studies that have reported negative cross-resistance or no difference in resistance, the first $(\mathrm{A})$ and the subsequent parasite $(\mathrm{B}, \mathrm{C})$ to which the host was exposed to, belonged to different taxonomic groups $[10,13,23,29]$. These observations hint that relatedness of the parasite is of relevance for the occurrence of different types of cross-resistance. In D. melanogaster that evolved with P. entomophila by oral infection, Martins et al. [10] observed that positive cross-resistance to the closely related P. putida was observed only upon oral infection and not when the flies were infected systemically (i.e. cuticular breaching); indicating that route of infection might be an important factor in cross-resistance. Adaptations to different routes have been shown to have different genetic underpinnings. In a study by Behrens et al. [30], it was shown that Tribolium castaneum has different gene expression profiles upon oral and systemic infection by the same parasite.

Although evolutionary studies of cross-resistance have been carried out, cross-resistance in a host arising out of experimental host-parasite coevolution (i.e., both the host and parasite are allowed to adapt to each other over time [31]) has so far not been investigated. Here, we investigate cross-resistance in hosts adapted to a single parasite species (A) under coevolutionary conditions upon exposure to unrelated parasites $(B, C)$. We conducted the present study with the following aims: (i) Does coevolution with a parasite result in cross-resistance to an unrelated parasite? (ii) Does the route of infection play a role in cross-resistance to unrelated parasites? The beetle T. castaneum, which had evolved under conditions allowing for host-parasite coevolution with the fungal parasite B. bassiana $[32,33]$ was the host for the experiments mentioned in our paper. During the evolution experiment [32,33], B. bassiana was present in the environment of the beetles, thereby, allowing for infection to occur naturally. We performed survival assays with the entomopathogenic bacteria Bacillus thuringiensis bv. tenebrionis (Gram positive; B. thuringiensis henceforth) and P. entomophila (Gram negative), and additionally with non-evolved B. bassiana and tested the gene expression profiles of $T$. castaneum evolved with B. bassiana upon exposure to B. thuringiensis, P. entomophila and non-evolved B. bassiana. B. thuringiensis and P. entomophila are phylogenetically distinct entomopathogenic bacteria, belonging to distinct clades of the bacterial phylogenetic tree [34]. Our results indicate that cross-resistance evolved towards $B$. thuringiensis as a consequence of coevolution with B. bassiana and that cross resistance is potentially due to a shared route of infection between B. bassiana and B. thuringiensis.

\section{Materials and Methods}

\subsection{Host}

The red flour beetle T. castaneum (from ancestral CRO1 population [35]) were used as hosts. Experimental coevolution was performed prior to the start of the experiments described in this paper. T. castaneum hosts and the parasite B. bassiana were allowed to evolve in each other's presence at a starting concentration of $10^{8}$ spores $\cdot \mathrm{g}^{-1}$ of $B$. bassiana for 13 host generations [32]. B. bassiana initially had a strongly negative influence on host fitness [33]. Control treatments were run in parallel without B. bassiana in the environment. Seven independent selection lines were produced for each treatment. Coevolution was allowed to occur for 13 host generations, followed by one generation of relaxed selection without the presence of B. bassiana in any regime resulting in generation 13 . After which F1 adults were generated and maintained without the presence of B. bassiana, in clean flour-mix [32] to minimise potential maternal effects and the influence of transgenerational immune priming [36]. A schematic of the evolution experiment can be found in [32], Figure 1. All of the survival assays and gene expression experiments here were conducted on the F2 of beetles from generation 13, maintained under standard rearing conditions for T. castaneum (dark, at $32{ }^{\circ} \mathrm{C}$ with $70 \%$ relative humidity) in a $5 \%$ $w / w$ mixture of brewer's yeast and organic wheat flour (type 405, Alnatura). The flour-mix serves as the beetles' immediate environment, as well as food resource. Throughout this paper, we refer to the hosts as 'Control' for beetles originating from populations evolved without the presence of 
B. bassiana and 'Coevolved' for those originating from populations forced to evolve with B. bassiana in the environment. Both 'Control' and 'Coevolved' selection regimes were simultaneously performed on seven replicate populations.

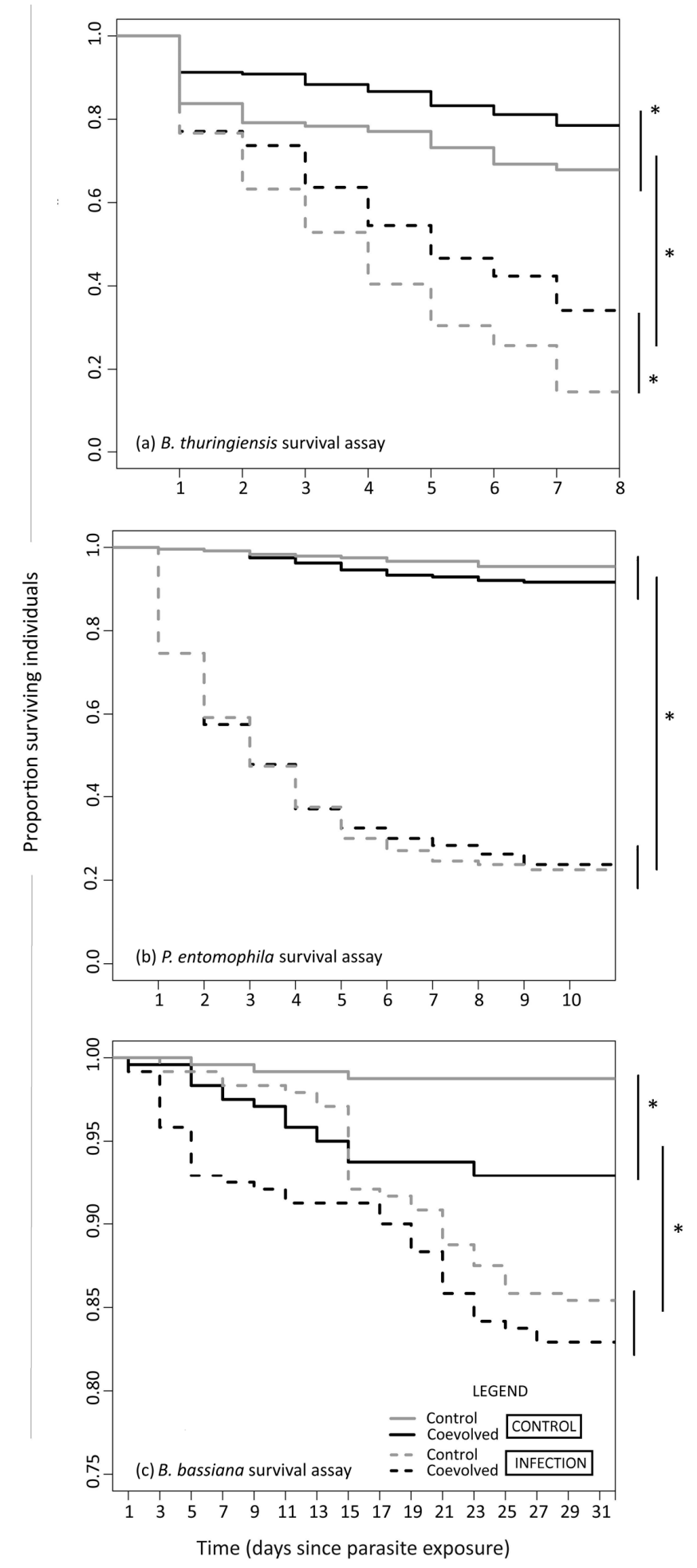

Figure 1. Survival of B. bassiana coevolved beetles upon infection upon exposure to non-evolved (a) B. thuringiensis, (b) P. entomophila, and (c) B. bassiana. * denotes significance between groups. Note: $\mathrm{y}$-axis in (a) starts from 0.75 for better visualization of data. 


\subsection{Parasites}

All of the parasites were cultivated from their respective glycerol stocks (50\% glycerol, Carl-Roth) stored at $-80^{\circ} \mathrm{C}$. B. thuringiensis was cultured strictly as per the protocol in Milutinovic et al. [35], allowing for the production of spores which in turn produce $\mathrm{Cry}$ toxins. P. entomophila was grown overnight in LB medium (Carl-Roth) in a $250 \mathrm{~mL}$ culture flask at $30^{\circ} \mathrm{C}$ and under shaking conditions of 200 RPM. The overnight culture of P. entomophila was centrifuged at $3200 \mathrm{G}$-force to obtain bacterial pellets while the culture supernatant was discarded. The pellets thus obtained were suspended in Phosphate Saline Buffer $(\mathrm{pH}=7)$ prior to use in survival assay. Non-evolved B. bassiana was plated on Potato-Dextrose agar (Carl-Roth) and stored at room temperature for 2-3 weeks prior to spore collection.

\subsection{Survival Assays}

Of the seven replicates beetle populations per selection regime, five populations from the 'Control' and 'Coevolved' regimes were used for the survival assays. F1 adult beetles belonging to generation 13 of the coevolution experiment [32] were set up for mating and egg laying for three days. At the end of this period, adults were removed and the eggs were allowed to develop under standard beetle rearing conditions for 10 days. Throughout this paper, we refer to treatments in the infection and gene expression experiments as CONTROL (not exposed to parasites) and INFECTION (exposed to a specific number of parasites). Survival assays were performed on the resulting F2 larvae, to control for maternal effects, on the 10th day post adult removal. Forty larvae per beetle population per treatment $((5 \times 40)+(5 \times 40)=400$ in total $)$ were used in each of the survival assays.

B. thuringiensis survival assay was performed in a 96-well plate (Greiner Bio-one) setup with a spore concentration of $5 \times 10^{9}$ spores $\mathrm{mL}^{-1}$ of flour-mix \& Phosphate buffer saline (PBS, $\mathrm{pH}=7$ ) solution, in line with Milutinovic et al. [35]. On the first day, 96-well plates containing $40 \mu \mathrm{L}$ per well of either flour-mix with $B$. thuringiensis spore suspension or flour-mix with sterile Phosphate Buffer solution (PBS; $\mathrm{pH}=7.0$ ) were prepared, which were dried overnight at $50{ }^{\circ} \mathrm{C}$. The next day, one larva per well was placed in the dried 96-well plates, with each plate containing two replicate populations per treatment. Finally, each plate was sealed with transparent sticky tape and three holes using board pins were punctured on top of each well to allow air circulation. These were then put in plastic boxes that were stored under standard rearing conditions. Each 96-well plate that was set up contained only one treatment and larval survival was observed for seven days on a daily basis.

For the P. entomophila survival assay, larvae were infected systemically the protocol by Roth et al. [37]. Individual larva was pricked in the pronotum, on the left dorsal side, with a needle (diameter $=0.05 \mathrm{~mm}$ ) dipped in either $5 \times 10^{9}$ spores $\mathrm{mL}^{-1}$ of $P$. entomophila spore suspension or sterile PBS, for INFECTION and CONTROL treatments, respectively. Post pricking, larvae were individualised in 96-well plates containing $40 \mu \mathrm{L}$ of flour-mix \& PBS solution dried overnight at $50{ }^{\circ} \mathrm{C}$ in a manner similar to that for $B$. thuringiensis survival assay. Survival was recorded every day for a period of 10 days.

For B. bassiana survival assay, larvae were placed individually in small glass vials $(40 \mathrm{~mm} \times 13 \mathrm{~mm}$, Carl-Roth) with $0.17 \mathrm{~g}$ mixture of flour-mix containing $10^{8}$ of B. bassiana spores $\cdot \mathrm{g}^{-1}$ for INFECTION treatment and vials were capped with cotton wool stoppers (Carl-Roth). For CONTROL, larvae were placed in glass vials containing just $0.17 \mathrm{~g}$ of flour-mix. Since B. bassiana is a slow killer of T. castaneum, survival was monitored every alternate day for a period of 30 days (See Supplementary Materials File 1 for daily survival for each assay).

\subsection{Host Treatment Prior to Investigating Gene Expression}

Since there was no difference between the different replicate populations within each treatment, we selected two replicate $B$. bassiana coevolved beetle populations that showed the highest numerical survival (absolute number of individuals surviving out of the 40 individuals treated per population) at 
the end of the assay, for investigating gene expression as logistically we could not test all populations. Adults were set up for mating and egg laying as mentioned before and the larvae could develop. Following this, larvae were infected as per the methods that are described in the survival assay with B. thuringiensis, P. entomophila and B. bassiana individually. For CONTROL, the coevolved larvae were not exposed to parasites but handled similarly. Post treatment, the larvae were placed under standard rearing conditions for beetles. For each parasite, larvae were sampled from both CONTROL and INFECTION treatments 12 and $24 \mathrm{~h}$ post exposure. These two time-points were chosen based on previous transcriptomic studies using B. thuringiensis [30] and B. bassiana [32]. After collection larvae were immediately snap frozen in liquid nitrogen and stored at $-80{ }^{\circ} \mathrm{C}$ until RNA extraction.

\subsection{RNA Extraction and cDNA Synthesis}

RNA was extracted from pools of 15 larvae (per treatment and time-point). The samples were homogenized $(2 \times 30 \mathrm{~s})$ in $2 \mathrm{~mL}$ Eppendorf tubes with one $5 \mathrm{~mm}$ diameter stainless steel bead (Qiagen, Hilden, Germany) per tube. Each tube contained $400 \mu \mathrm{L}$ of TRI reagent (Sigma-Aldrich (Merck), Darmstadt, Germany), using Tissue-lyser II (Qiagen) at $30 \mathrm{~Hz}$ for $2 \times 30 \mathrm{~s}$. Further treatment for RNA extraction was performed on this homogenate using Direct-zol ${ }^{\mathrm{TM}}$ RNA MiniPrep kit (Zymo Research, Irvine, CA, USA) as per the specifications in the manufacturer's protocol. RNA concentration and purity were determined spectrophotometrically (Take3, BioTek, Bad Friedrichshall, Germany) and quality was checked using agarose gel electrophoresis with $1 \times$ TAE buffer. RNA samples with a quality ratio of $\mathrm{A}_{260} / \mathrm{A}_{280}$ (residual phenolic contamination) and $\mathrm{A}_{260} / \mathrm{A}_{230}$ (nucleic acid purity) 2 containing two sharp bands representing $23 \mathrm{~S}$ and $18 \mathrm{~S}$ rRNA were used for cDNA synthesis, in accordance with MIQE guidelines [38]. Unsatisfactory RNA samples were concentrated using 100\% ethanol and $3 \mathrm{M}$ Sodium Acetate (Thermo-Fisher Scientific, Schwerte, Germany), as per the standard protocol. For cDNA synthesis, $2 \mu \mathrm{g}$ of total RNA, oligo $(\mathrm{dT})_{18}$ primers and the reagents from the First Strand cDNA Synthesis Kit (Thermo-Fisher Scientific) were used in accordance with the manufacturer's protocol. The resulting cDNA was diluted to a working concentration of $10 \mathrm{ng} \cdot \mu \mathrm{L}^{-1}$, and stored in separate $1 \mathrm{~mL}$ Eppendorf tubes at $-80^{\circ} \mathrm{C}$ until used.

\subsection{Candidate Genes and Primer Validation}

We surveyed existing literature for T. castaneum genes expressed post infection and decided on representative candidate genes enlisted in Supplementary Materials File 2, Table S1. We selected candidate genes based on a survey of existing gene expression studies which span RT-qPCR [39], transcriptomic [30] and functional analysis [40-42] approaches. The genes tested represent stress (Hsp90, p450), phenoloxidase (PO) (Laccase-2 (Lac-2; [40]) and Apolipophorin-III (Apo-III; [30,42])) and antimicrobial peptides (Attacin-2 (Atta-2) \& Defensin-3 (Def-3) [39]). Additionally candidates for external immune defence (quinone-related; Gt39 [43]), expressed upon fungal challenge (Thaumatin-like; Thaumatin [39]), for innate immunity (Lysozyme (Lyso-4; [30])) and chitin metabolism (chitin deacetylase (TcDA6; [41])) were analysed. Among these, markers for oral (Apo-III \& ObpC-12) and systemic (Hsp-90 \& p450) routes of infection were used to test our hypothesis that cross-resistance is route dependent. Gene-specific primers (biomers.net) were designed using Oligo Explorer v1.1.2 (available online at http:/ / www.genelink.com/tools/gl-oe.asp). All primers were designed to have 19-23 nucleotides with a $\mathrm{T}_{\mathrm{m}} \sim 60^{\circ} \mathrm{C}$ and amplification products of length 70-150 base-pairs (bp). The volume of the reaction was $10 \mu \mathrm{L}$, containiing $5 \mu \mathrm{L}$ Power SYBR Green PCR Master Mix (Applied Biosystems, Darmstadt, Germany), $1 \mu \mathrm{L}$ (10 ng) of cDNA and specific forward and reverse primer different concentrations (150 nM, $300 \mathrm{nM}, 450 \mathrm{nM}$ and $900 \mathrm{nM}$ in a full-factorial manner), with remaining volume scaled up with water in order to determine the optimum forward to reverse primer ratios.Primers were tested on cDNA prepared from stock CRO1 T. castaneum in a melt curve assay to determine the optimum forward to reverse primer ratio, as mentioned in Supplementary Materials File 2, Table S2, followed by a standard curve assay using the StepOnePlus Real-Time PCR System (Applied Biosystems) to determine primer efficiencies (Supplementary Materials File 2, Table S1). The 
total reaction volume was 10 we used cDNA concentrations spanning 0.001 to $100 \mathrm{ng}$ in 5-fold dilutions with the cycling conditions as described in the following for performing standard curve analyses. Hot-start PCR with denaturation at $95^{\circ} \mathrm{C}$ was run for $10 \mathrm{~min}$ followed by 40 cycles of extension at $95^{\circ} \mathrm{C}$ for $15 \mathrm{~s}$ and at $60^{\circ} \mathrm{C}$ for $60 \mathrm{~s}$. Finally melt curve analysis was run with a step-wise temperature increment from $60{ }^{\circ} \mathrm{C}$ to $95{ }^{\circ} \mathrm{C}$ in steps of $0.5^{\circ} \mathrm{C}$. Primer efficiency was calculated using StepOne Software v2.3 (Thermo-Fisher Scientific) and only primers with an efficiency of $85-110 \%$, regression fit of $R^{2} \geq 0.98$ and a single sharp melt curve peak corresponding to specific amplification were used for RT-qPCR experiments. Additionally, all primers were tested with water and stock CRO1 mRNA as template to check for primer dimers and unspecific amplifications, respectively (here $C_{t}$ or threshold cycle was set at $C_{t} \geq 40$ as per MIQE guidelines [38]). Only the primer pairs for the amplifications occurred at $C_{t} \leq 20$ were included in the analysis.

\subsection{Gene Expression Using Quantitative PCR}

Quantitative real-time RT-PCR was carried out on a StepOnePlus system (Applied Biosystems) using optical 96-well plates (Applied Biosystems) and covered with MicroAmp ${ }^{\mathrm{TM}}$ optical adhesive film (Thermo Fischer Scientific). The total reaction volume of $10 \mu \mathrm{L}$ contained $5 \mu \mathrm{L}$ Power SYBR Green PCR Master Mix (Applied Biosystems), $1 \mu \mathrm{L}$ (10 ng) of cDNA, specific forward and reverse primer concentrations (Supplementary Materials File 2, Table S2) with remaining volume scaled up with water. All of the reactions were carried out in three technical replicates under the reaction conditions stated above. Baseline correction was performed automatically by StepOne Software v2.3. Reactions for reference genes Rps3 and Rps18 [44] were performed on every 96-well plate setup, to normalise gene expressions. Additionally, two technical replicate reactions were performed in each of the 96-well plates, for no-reverse transcription and RNA control (to control for unspecific amplification with genomic DNA), in accordance with the MIQE guidelines [38]. Here, amplifications before $\leq 30 C_{t}$ were included in the analysis.

\subsection{Statistical Analysis}

All data were statistically analysed using R software version 3.2.3 (Vienna, Austria) for statistical programming [45].

\subsection{Survival Analysis}

Since the survival data did not meet the assumptions of normality, we performed non-parametric Kaplan Meier analysis using the package 'survival' in R [46]. Multiple pairwise comparisons of survival curves were performed using an adaptation of a code by Terry Therneu, the results of which were corrected using Holm method.

\subsection{Gene Expression Analysis}

Gene expression data from RT-qPCR (Supplementary Materials Files 3 and 4) were analysed using the MCMC.qpcr R package [47,48], which implements a generalized linear mixed model analysis of qPCR data. We used the 'classic' mode, which normalizes the expression data of different candidate genes relative to 'control' genes (reference genes). We constructed a full factorial model with 'Treatment' and 'Timepoint' as interaction terms. P-values were adjusted for multiple comparisons using the Benjamini \& Hochberg correction method implemented in the 'p.adjust' function d in R.

\section{Results}

\subsection{B. bassiana Coevolved Beetles Are Positively Cross-Resistant to B. thuringiensis}

Survival of F2 larvae of generation 13 beetles from the coevolution experiment was recorded for a period of 7, 10, and 30 days post exposure to, B. thuringiensis, P. entomophila, and B. bassiana, respectively. 
In the $B$. thuringiensis assay, survival of groups within INFECTION and CONTROL treatments were significantly different from each other $\left(\chi^{2}=224,3\right.$ Degrees of Freedom $\left.(\mathrm{DF})=3, p<0.001\right)$. Pairwise comparison of Kaplan-Meier curves (Figure 1a and Table 1) show that 'Control' and 'Coevolved' groups differ in CONTROL treatment $(p=0.05)$, and highly differ in INFECTION treatment $(p<0.001)$. Here, higher survival of coevolved beetles upon INFECTION, in comparison to their control counterparts indicates positive cross-resistance to $B$. thuringiensis upon oral infection.

Table 1. Results ( $p$-values) of pairwise-wise comparison of survival curves using log-rank tests followed by Holm correction.

\begin{tabular}{cccc}
\hline \multirow{2}{*}{ Origin $\times$ Treatment } & \multicolumn{3}{c}{ B. thuringiensis Survival Assay } \\
\cline { 2 - 4 } & ‘Coevolved' CONTROL & 'Control' CONTROL & `Coevolved' INFECTION \\
\hline 'Control' CONTROL & 0.05 & $<0.001$ & \\
'Coevolved' INFECTION & $<0.001$ & $<0.001$ & $<0.001$ \\
'Control' INFECTION & $<0.001$ & P. entomophila survival assay & \\
\hline & & & \\
\hline & 0.19 & $<0.001$ & \\
\hline 'Control' CONTROL & $<0.001$ & $<0.001$ & \\
'Coevolved' INFECTION & $<0.001$ & B. bassiana survival assay & \\
'Control' INFECTION & & & \\
\hline & 0.004 & $<0.001$ & 0.397 \\
\hline 'Control' CONTROL & 0.003 & $<0.001$ & \\
'Coevolved' INFECTION & 0.022 & & \\
'Control' INFECTION &
\end{tabular}

Note: 'Control' and 'Coevolved' denote the evolutionary background of the hosts; CONTROL and INFECTION refer to the treatments in the survival assay.

In the P. entomophila assay, survival of groups in INFECTION and CONTROL treatments were significantly different from each other $\left(\chi^{2}=544, \mathrm{DF}=3, p<0.001\right)$. Pairwise comparison of Kaplan-Meier curves (Figure $1 \mathrm{~b}$ and Table 1.) show that 'Control' and 'Coevolved' groups do not differ from each other in either CONTROL $(p=0.19)$ or INFECTION $(p=0.80)$. This indicates that $B$. bassiana coevolved beetles are neither positively or negatively cross-resistant to P. entomophila upon systemic infection.

In the B. bassiana assay, survival of groups in INFECTION and CONTROL treatments were significantly different from each other $\left(\chi^{2}=41.1, \mathrm{DF}=3, p<0.001\right)$. Pairwise comparison of Kaplan-Meier curves (Figure 1c and Table 1) revealed that 'Control' and 'Coevolved' groups differ from each other within CONTROL ( $p=0.004)$, but not within INFECTION treatment $(p=0.397)$, with the 'Control' group surviving better than 'Coevolved' group.

\subsection{Gene Expression Analysis Reveals Expression of Markers for Oral Toxicity upon B. bassiana Exposure}

We used RT-qPCR to investigate differences in the expression of 11 candidate genes post B. bassiana, B. thuringiensis and P. entomophila on F2 larvae of generation 12 beetles evolved with B. bassiana under conditions allowing for coevolution. The larvae were sampled for RT-qPCR experiments 12 and $24 \mathrm{~h}$ post exposure. Most of the candidate genes were up-regulated $12 \mathrm{~h}$ post $\mathrm{B}$. thuringiensis exposure with markers for stress, Hsp90 (3 fold) and p450 (6.6 fold) being prominent (Figure 2a), implying cross-talk between immune and stress response $[39,49]$. $24 \mathrm{~h}$ post $B$. thuringiensis exposure showed up-regulation in all of the candidate genes. When compared to $12 \mathrm{~h}$, stress markers Hsp90 (1.35 fold) and p450 (1.65 fold) were less up-regulated. Additionally, the innate immunity marker, Lysozyme was up-regulated (Figure 2a). $12 \mathrm{~h}$ post P. entomophila exposure Attacin-2 (411 fold) and Thaumatin (34 fold) were highly up-regulated (Figure 2b). This observation is in consensus with previous findings reporting the expression of these genes upon Gram negative bacterial exposure [49-51]. Here, no change in gene expression pattern (up or down-regulation) was observed at $24 \mathrm{~h}$ compared to $12 \mathrm{~h}$, expression levels of Attacin-2 (84 fold) and Thaumatin (13.22 fold) decreased (Figure 2b). $12 \mathrm{~h}$ post 
B. bassiana exposure, Apo-III (8.63 fold) and ObpC-12 ( 8 fold) were up-regulated but not Thaumatin (Figure 2c). Upregulation of Apo-III (8.84 fold) and ObpC-12 (18 fold) was observed 24 post B. bassiana exposure as well (Figure 2c).
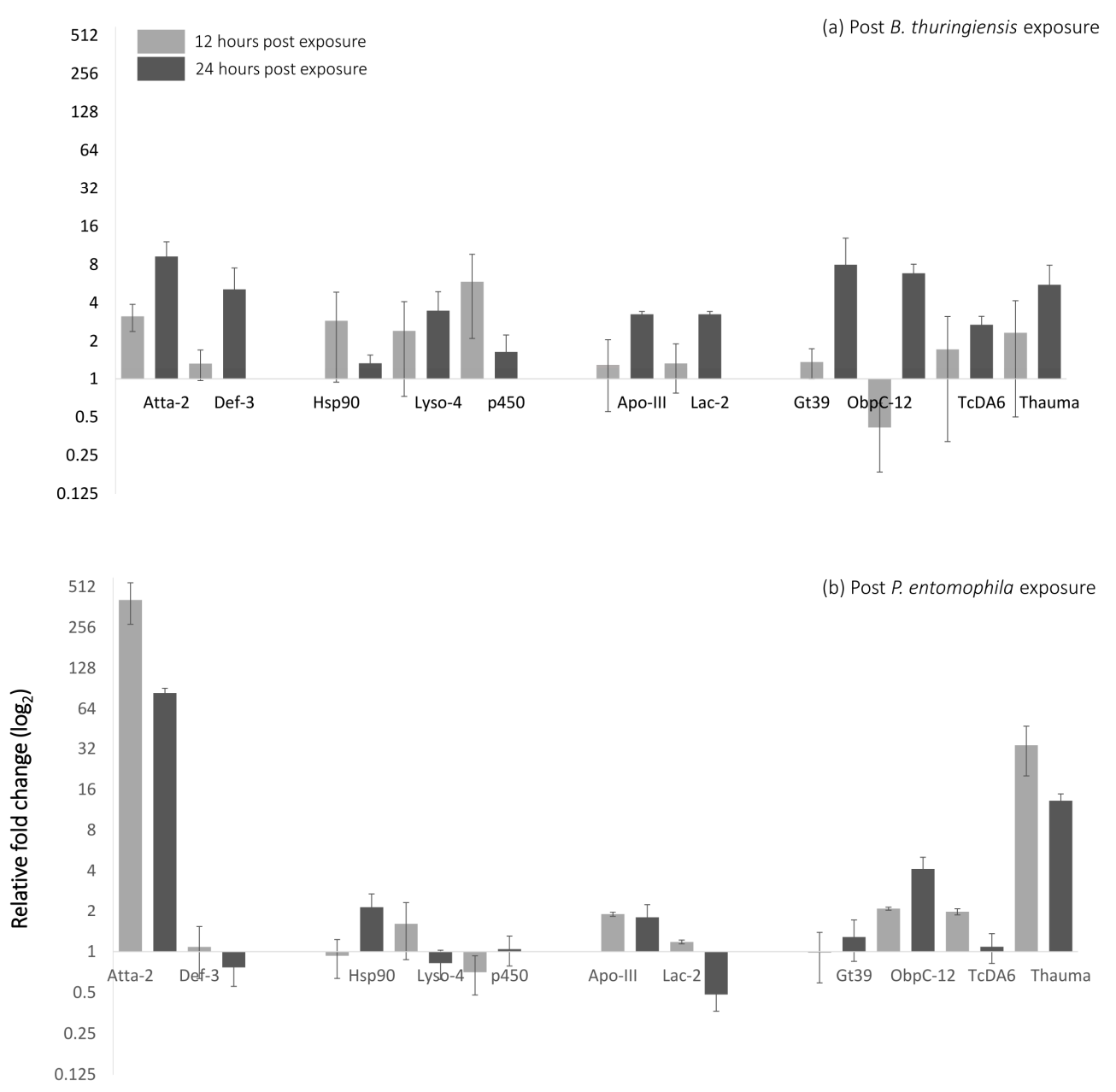

(c) Post B. bassiana exposure

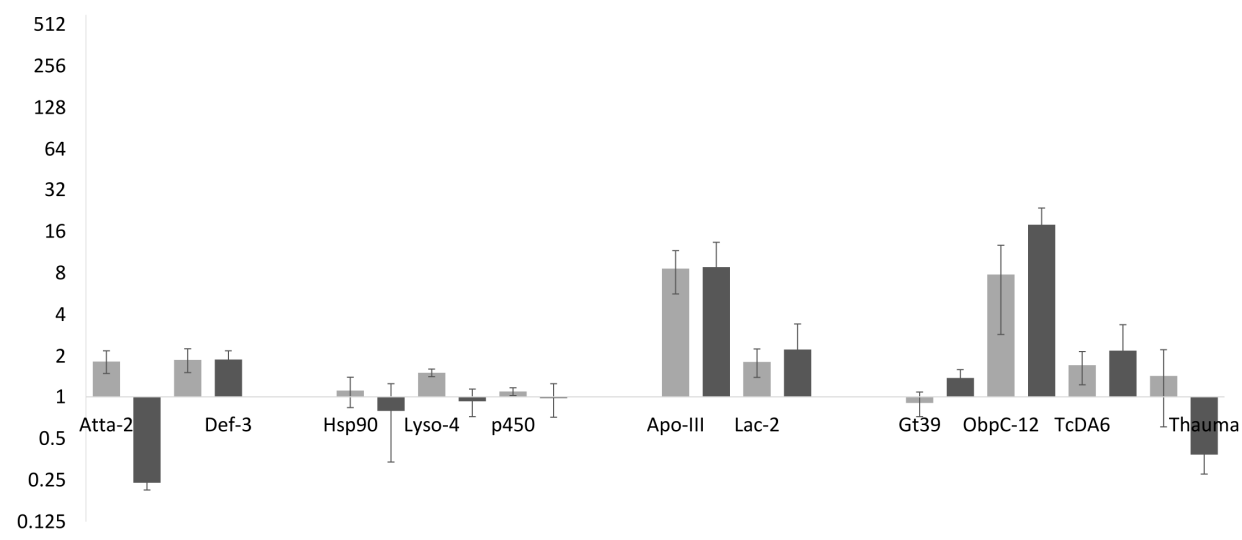

Candidate genes

Figure 2. RT-qPCR results on the coevolved beetles (relative to coevolved beetles not exposed to parasites) upon exposure with ((a) B. thuringiensis, (b) P. entomophila and (c) non-coevolved B. bassiana, 12 and $24 \mathrm{~h}$ post exposure (see Supplementary Materials File 5, Table S1 for fold change values). The route of parasite entry for the qPCR was kept the same as that used for the survival assay. (Error bars indicate $( \pm)$ standard errors of the mean). 
Changes in gene expression upon B. thuringiensis, P. entomophila and B. bassiana exposures with respect to time (12 vs. $24 \mathrm{~h}$ ) and treatment (CONTROL vs. INFECTION) are summarized in Figure 3. Here too, differential expression of greater number of candidate upon B. thuringiensis infection than other exposures (Figure 3) is observed. In general, we observed more genes being differentially expressed with respect to time than to treatment.

\begin{tabular}{|c|c|c|c|c|c|c|c|c|c|}
\hline & \multicolumn{3}{|c|}{ B. Thuringiensis } & \multicolumn{3}{|c|}{ P. entomophila } & \multicolumn{3}{|c|}{ B. bassiana } \\
\hline & Time & Treatment & \begin{tabular}{|l|} 
Time \& \\
Treatment
\end{tabular} & Time & Treatment & $\begin{array}{l}\text { Time \& } \\
\text { Treatment }\end{array}$ & Time & Treatment & \begin{tabular}{|l|} 
Time \& \\
Treatment
\end{tabular} \\
\hline \multicolumn{10}{|l|}{ Atta-2 } \\
\hline \multicolumn{10}{|l|}{ Def-3 } \\
\hline \multicolumn{10}{|l|}{ Hsp90 } \\
\hline \multicolumn{10}{|l|}{ Lyzo-4 } \\
\hline \multicolumn{10}{|l|}{ P450 } \\
\hline \multicolumn{10}{|l|}{ Apo-III } \\
\hline \multicolumn{10}{|l|}{ Lac-2 } \\
\hline \multicolumn{10}{|l|}{ Gt39 } \\
\hline \multicolumn{10}{|l|}{ Obpc12 } \\
\hline \multicolumn{10}{|l|}{ TcDA6 } \\
\hline \multicolumn{10}{|l|}{ Thaumatin } \\
\hline \multicolumn{8}{|c|}{$\begin{array}{l}\text { Highlighted fields depict changes in gene expression of candidate genes post normalization using } \\
\text { reference genes. Significance of the factors are given as follows: Time is computed as change after } \\
24 \text { hours compared to } 12 \text { hours only, Treatment is computed as change upon infection only and the } \\
\text { interaction term 'Time \& Treatment' refers to changes after } 24 \text { hours compared to } 12 \text { hours upon } \\
\text { INFECTION (vs CONTROL). }\end{array}$} & \multicolumn{2}{|c|}{ P-value color key } \\
\hline
\end{tabular}

Figure 3. Results from the analysis of differential relative gene expression upon parasite exposure via generalized linear mixed models performed using the R package MCMC.qpcr [47,48]. See Supplementary Materials File 5, Table S2 for corresponding $p$-values.

\section{Discussion}

Here, we present the first report of evolutionary positive cross-resistance in T. castaneum, as a consequence of coevolution with B. bassiana, which is shown towards B. thuringiensis upon oral exposure, but not upon systemic exposure with $P$. entomophila. This observation is mirrored in expression pattern of host genes related to resistance to oral toxicity upon B. bassiana exposure. It has been reported that oral infection with $B$. thuringiensis and exposure to coleopteran specific Cry-III toxins leads to the expression of several odorant-binding proteins [30,52] and Apolipophorins [30,42] in T. castaneum. We observed an upregulation in Apo-III and ObpC-12, our markers for oral infection, upon B. bassiana exposure. Infection with Gram-negative P. entomophila caused no variation in coevolved T. castaneum larvae neither in survival assay nor qPCR. The up-regulation of Atta-2 is consistent with reports that show the expression of this anti-microbial peptide upon Gram-negative bacteria infection [51]. Due to the constant presence of B. bassiana during coevolution [32], there was a high chance of T. castaneum ingesting B. bassiana spores. Furthermore, there is some evidence that $B$. bassiana may be able to infect orally [53,54], although this is yet to be mechanistically proven. This occurrence potentially led to T. castaneum adapting to oral infection. This is consistent with previous findings that the coevolved beetles have more flexible PO responses that vary depending on infection route, indicating that during the course of coevolution, B. Bassiana adapted to infecting the host orally [33]. Together, the response of coevolved beetles to B. bassiana and B. thuringiensis exposure imply that similar defence mechanisms are effective against both of the parasites. Here, it is imperative to mention that the overserved response of the coevolved hosts could have been influenced by carried over maternal 
effects, due to constant exposure of the previous generations to parasites in the environment. However, immune priming has not been consistently observed in insects exposed to B. bassiana [55] and to date all transgenerational immune priming seen in T. castaneum has been over a single generation $[36,37,56]$. Therefore, parental priming to $B$. bassiana is unlikely to be an adequate explanation to our results.

Positive cross-resistance is more likely to occur if the defence mechanisms employed by the host towards the two parasites are similar or shared, owing to a similarity in the route of parasite entry and/or mechanism of infection [23]. Oral toxicity of B. thuringiensis is mediated by the production of Cry toxins that solubilise in the insect midgut due to a change in $\mathrm{pH}$ and disrupt peritrophic membrane integrity $[57,58]$. B. bassiana is known to infect by germination of spores on the insect cuticle followed by cuticular breaching through hyphae [53,59]. That B. bassiana possesses the ability to infect orally has been a matter of speculation with some experimental evidence [54,60]. For example, in the red imported ant Solenopsis invicta, B. bassiana was shown to successfully infect via oral ingestion of conidia [54]. Furthermore, through comparative genome analysis, Xiao and colleagues found that in contrast to other entomopathogenic fungi, B. bassiana possess Cry-like toxin coding regions [61]. Our findings of cross-resistance towards B. thuringiensis upon coevolution with B. bassiana coupled with the expression of oral infection marker upon B. bassiana exposure, suggest that B. bassiana and B. thuringiensis share a similar infection route.

Behrens et al. [30] showed that the transcriptomic response of T. castaneum larvae differs based on the natural (oral) and artificial (systemic) routes via which B. thuringiensis infects the beetle. Experimental evolution of D. melanogaster to P. entomophila via oral and systemic routes, separately, revealed that adaptation to different routes was specific; flies adapted to one infection route were not resistant to $P$. entomophila infection via the route that they had not evolved to [10]. Indeed, the route of infection is important as the host physiological response may vary based on different routes. Our observations that the candidate gene for oral infection (ObpC-12) is expressed upon B. bassiana infection coupled with the fact that genomic analyses of B. bassiana reveals potential oral toxicity [61] and that $B$. bassiana coevolved beetles are positively cross-resistant to $B$. thuringiensis supports the argument that $B$. bassiana is able to infect orally [54,61].

Experimental evolution of insect hosts with $B$. bassiana provides contrasting results in terms of evolution of host resistance. While increase in resistance to B. bassiana was reported for G. melonella [11], evolved populations of $D$. melanogaster displayed no change in resistance towards B. bassiana [62]. In our study, 'Coevolved' T. castaneum larvae showed no difference in survival following exposure to B. bassiana when compared to 'Control' larvae. They do, however, buffer their fitness across evolutionary time by maintaining, or in the highest infection load treatment increasing pupae numbers when challenged with $B$. bassiana during coevolution and show infection route specific changes in phenoloxidase activity [33], implying some level of underlying resistance towards B. bassiana. The increased survival we observe here following $B$. thuringiensis infection adds support to the hypothesis that oral infection by $B$. bassiana drove selection specifically against oral infection.

Our results also have wider ecological and applied implications. B. bassiana spore suspensions and $B$. thuringiensis strains specific to different pest insect orders are widely used as biological control agents $[63,64]$. Prior exposure to $B$. bassiana could potentially lead to positive ecological cross-resistance in pest insects when exposed to $B$. thuringiensis strains and vice-versa, with implications in sustainable pest management. Positive cross-resistance can be beneficially applied by providing controlled doses of a parasite that protects against attacks by a more harmful parasite. This is similar to the application of probiotics in the culture of insects for food and feed [65]. Further research is warranted in the beneficial effects of positive cross-resistance for rearing beneficial insects.

\section{Conclusions}

We observe positive cross resistance of T. castaneum beetles coevolved with B. bassiana towards B. thuringiensis. We propose that this observation could be based on similarity in the route of entry and/or mechanism of infection between the two parasites. Supporting this hypothesis, RT-qPCR 
experiments performed in this study indicate that $B$. bassiana can induce expression of host genes that are related to oral toxicity. Adaptations of beetles to oral infection by B. bassiana may have led to positive cross-resistance in the coevolved beetles upon infection with $B$. thuringiensis. We thereby support the fact that the route of infection is highly important in host-parasite interactions and the physiological response of the host, as well as that of the parasite warrant more research.

Supplementary Materials: The following are available online at http:/ www.mdpi.com/2075-4450/9/1/28/s1, File 1: Survival data, File 2: Information regarding the primers used for RT-qPCR, File 3: qPCR 12 h, File 4: q PCR $24 \mathrm{~h}$, File 5: Results from gene expression.

Acknowledgments: Special thanks to Andreas Vilcinskas and Thorben Grau for comments on an earlier version of the manuscript. Thanks also to Gerrit Eichner for statiscal advice. The project was funded by a German Science Foundation grant (DFG-SPP 1399, JO 962/1-1) and a Volkswagen advanced postdoctoral grant awarded to Gerrit Joop (87133). Additionally, Charlotte Rafaluk was supported by the International Max Planck Research School for Evolutionary Biology at CAU Kiel; and Tilottama Biswas and Gerrit Joop within the LOEWE Centre for Insect Biotechnology and Bioresources (ZIB) in association with Andreas Vilcinskas, granted by the German state of Hessen's excellence initiative.

Author Contributions: Tilottama Biswas and Gerrit Joop conceived and designed the experiments; Tilottama Biswas performed the experiments and analyzed the data; The B. bassiana coevolved beetles were produced by Charlotte Rafaluk-Mohr; all authors contributed equally to the writing of the paper.

Conflicts of Interest: The authors declare no conflict of interest. The founding sponsors had no role in the design of the study; in the collection, analyses, or interpretation of data; in the writing of the manuscript, and in the decision to publish the results.

\section{References}

1. Bargielowski, I.; Koella, J.C. A Possible Mechanism for the Suppression of Plasmodium berghei Development in the Mosquito Anopheles gambiae by the Microsporidian Vavraia culicis. PLoS ONE 2009, 4, e4676. [CrossRef] [PubMed]

2. Betts, A.; Rafaluk, C.; King, K.C. Host and Parasite Evolution in a Tangled Bank. Trends Parasitol. 2016, 32, 863-873. [CrossRef] [PubMed]

3. Hafer, N.; Milinski, M. Inter- and intraspecific conflicts between parasites over host manipulation. Proc. $R$. Soc. B 2016, 283. [CrossRef] [PubMed]

4. Bordes, F.; Morand, S. Coevolution between multiple helminth infestations and basal immune investment in mammals: Cumulative effects of polyparasitism? Parasitol. Res. 2009, 106, 33-37. [CrossRef] [PubMed]

5. Start, D.; Gilbert, B. Host-parasitoid evolution in a metacommunity. Proc. R. Soc. B 2016, 283, 20160477. [CrossRef] [PubMed]

6. De Roode, J.C.; Culleton, R.; Cheesman, S.J.; Carter, R.; Read, A.F. Host heterogeneity is a determinant of competitive exclusion or coexistence in genetically diverse malaria infections. Proc. Biol. Sci. 2004, 271, 1073-1080. [CrossRef] [PubMed]

7. Hatcher, M.J.; Dick, J.T.; Dunn, A.M. Diverse effects of parasites in ecosystems: Linking interdependent processes. Front. Ecol. Environ. 2012, 10, 186-194. [CrossRef]

8. Von Beeren, C.; Maruyama, M.; Hashim, R.; Witte, V. Differential host defense against multiple parasites in ants. Evol. Ecol. 2010, 25, 259-276. [CrossRef]

9. Fellowes, M.D.E.; Kraaijeveld, A.R.; Godfray, H.C.J. Cross-Resistance Following Artificial Selection for Increased Defense against Parasitoids in Drosophila melanogaster. Evolution 1999, 53, 966-972. [CrossRef] [PubMed]

10. Martins, N.E.; Faria, V.G.; Teixeira, L.; Magalhães, S.; Sucena, É. Host Adaptation Is Contingent upon the Infection Route Taken by Pathogens. PLoS Pathog. 2013, 9, e1003601. [CrossRef] [PubMed]

11. Dubovskiy, I.M.; Whitten, M.M.A.; Yaroslavtseva, O.N.; Greig, C.; Kryukov, V.Y.; Grizanova, E.V.; Mukherjee, K.; Vilcinskas, A.; Glupov, V.V.; Butt, T.M. Can Insects Develop Resistance to Insect Pathogenic Fungi? PLoS ONE 2013, 8, e60248. [CrossRef] [PubMed]

12. Faria, V.G.; Martins, N.E.; Paulo, T.; Teixeira, L.; Sucena, É; Magalhães, S. Evolution of Drosophila resistance against different pathogens and infection routes entails no detectable maintenance costs. Evolution 2015, 69, 2799-2809. [CrossRef] [PubMed] 
13. Martins, N.E.; Faria, V.G.; Nolte, V.; Schlötterer, C.; Teixeira, L.; Sucena, É.; Magalhães, S. Host adaptation to viruses relies on few genes with different cross-resistance properties. Proc. Natl. Acad. Sci. USA 2014, 111, 5938-5943. [CrossRef] [PubMed]

14. Decaestecker, E.; Gaba, S.; Raeymaekers, J.A.M.; Stoks, R.; Van Kerckhoven, L.; Ebert, D.; De Meester, L. Host-parasite 'Red Queen' dynamics archived in pond sediment. Nature 2007, 450, 870-873. [CrossRef] [PubMed]

15. Schulte, R.D.; Makus, C.; Hasert, B.; Michiels, N.K.; Schulenburg, H. Host-parasite local adaptation after experimental coevolution of Caenorhabditis elegans and its microparasite Bacillus thuringiensis. Proc. R. Soc. Lond. B Biol. Sci. 2011, 278, 2832-2839. [CrossRef] [PubMed]

16. Schulte, R.D.; Makus, C.; Hasert, B.; Michiels, N.K.; Schulenburg, H. Multiple reciprocal adaptations and rapid genetic change upon experimental coevolution of an animal host and its microbial parasite. Proc. Natl. Acad. Sci. USA 2010, 107, 7359-7364. [CrossRef] [PubMed]

17. Bérénos, C.; Schmid-Hempel, P.; Wegner, K.M. Complex adaptive responses during antagonistic coevolution between Tribolium castaneum and its natural parasite Nosema whitei revealed by multiple fitness components. BMC Evol. Biol. 2012, 12, 11. [CrossRef] [PubMed]

18. Bérénos, C.; Schmid-Hempel, P.; Mathias Wegner, K. Evolution of host resistance and trade-offs between virulence and transmission potential in an obligately killing parasite. J. Evol. Biol. 2009, 22, 2049-2056. [CrossRef] [PubMed]

19. Bérénos, C.; Wegner, K.M.; Schmid-Hempel, P. Antagonistic coevolution with parasites maintains host genetic diversity: An experimental test. Proc. R. Soc. Lond. B Biol. Sci. 2010. [CrossRef]

20. Dupas, S.; Carton, Y.; Poiriè, M. Genetic dimension of the coevolution of virulence-resistance in Drosophila-Parasitoid wasp relationships. Heredity 2003, 90, 84-89. [CrossRef] [PubMed]

21. Kerstes, N.A.; Bérénos, C.; Schmid-Hempel, P.; Wegner, K.M. Antagonistic experimental coevolution with a parasite increases host recombination frequency. BMC Evol. Biol. 2012, 12, 18. [CrossRef] [PubMed]

22. Kraaijeveld, A.R.; Godfray, H.C.J. Trade-off between parasitoid resistance and larval competitive ability in Drosophila melanogaster. Nature 1997, 389, 278-280. [CrossRef] [PubMed]

23. Kraaijeveld, A.R.; Layen, S.J.; Futerman, P.H.; Godfray, H.C.J. Lack of Phenotypic and Evolutionary Cross-Resistance against Parasitoids and Pathogens in Drosophila melanogaster. PLoS ONE 2012, 7, e53002. [CrossRef] [PubMed]

24. Zuk, M.; Stoehr, A.M. Immune Defense and Host Life History. Am. Nat. 2002, 160, S9-S22. [CrossRef] [PubMed]

25. Koskella, B.; Lin, D.M.; Buckling, A.; Thompson, J.N. The costs of evolving resistance in heterogeneous parasite environments. Proc. R. Soc. Lond. B Biol. Sci. 2012, 279, 1896-1903. [CrossRef] [PubMed]

26. Scarborough, C.L.; Ferrari, J.; Godfray, H.C.J. Aphid Protected from Pathogen by Endosymbiont. Science 2005, 310, 1781. [CrossRef] [PubMed]

27. Parker, B.J.; Spragg, C.J.; Altincicek, B.; Gerardo, N.M. Symbiont-Mediated Protection against Fungal Pathogens in Pea Aphids: A Role for Pathogen Specificity? Appl. Environ. Microbiol. 2013, 79, 2455-2458. [CrossRef] [PubMed]

28. Xie, J.; Butler, S.; Sanchez, G.; Mateos, M. Male killing Spiroplasma protects Drosophila melanogaster against two parasitoid wasps. Heredity 2014, 112, 399-408. [CrossRef] [PubMed]

29. Bentz, M.L.; Humphrey, E.A.; Harshman, L.G.; Wayne, M.L. Sigma Virus (DMelSV) Incidence in Lines of Drosophila melanogaster Selected for Survival following Infection with Bacillus cereus. Psyche J. Entomol. 2017, 2017, e3593509. [CrossRef]

30. Behrens, S.; Peuß, R.; Milutinović, B.; Eggert, H.; Esser, D.; Rosenstiel, P.; Schulenburg, H.; Bornberg-Bauer, E.; Kurtz, J. Infection routes matter in population-specific responses of the red flour beetle to the entomopathogen Bacillus thuringiensis. BMC Genomics 2014, 15, 445. [CrossRef] [PubMed]

31. Brockhurst, M.A.; Koskella, B. Experimental coevolution of species interactions. Trends Ecol. Evol. 2013, 28, 367-375. [CrossRef] [PubMed]

32. Rafaluk, C.; Yang, W.; Mitschke, A.; Rosenstiel, P.; Schulenburg, H.; Joop, G. Highly potent host external immunity acts as a strong selective force enhancing rapid parasite virulence evolution. Environ. Microbiol. 2017, 19, 2090-2100. [CrossRef] [PubMed]

33. Rafaluk-Mohr, C.; Wagner, S.; Joop, G. Cryptic changes in immune response and fitness in Tribolium castaneum as a consequence of coevolution with Beauveria bassiana. J. Invertebr. Pathol. 2018, 152, 1-7. [CrossRef] [PubMed] 
34. Vodovar, N.; Vallenet, D.; Cruveiller, S.; Rouy, Z.; Barbe, V.; Acosta, C.; Cattolico, L.; Jubin, C.; Lajus, A.; Segurens, B.; et al. Complete genome sequence of the entomopathogenic and metabolically versatile soil bacterium Pseudomonas entomophila. Nat. Biotechnol. 2006, 24, 673-679. [CrossRef] [PubMed]

35. Milutinović, B.; Stolpe, C.; Peu $\beta$, R.; Armitage, S.A.O.; Kurtz, J. The Red Flour Beetle as a Model for Bacterial Oral Infections. PLoS ONE 2013, 8, e64638. [CrossRef] [PubMed]

36. Roth, O.; Joop, G.; Eggert, H.; Hilbert, J.; Daniel, J.; Schmid-Hempel, P.; Kurtz, J. Paternally derived immune priming for offspring in the red flour beetle, Tribolium castaneum. J. Anim. Ecol. 2010, 79, 403-413. [CrossRef] [PubMed]

37. Roth, O.; Sadd, B.M.; Schmid-Hempel, P.; Kurtz, J. Strain-specific priming of resistance in the red flour beetle, Tribolium castaneum. Proc. R. Soc. Lond. B Biol. Sci. 2009, 276, 145-151. [CrossRef] [PubMed]

38. Bustin, S.A.; Benes, V.; Garson, J.A.; Hellemans, J.; Huggett, J.; Kubista, M.; Mueller, R.; Nolan, T.; Pfaffl, M.W.; Shipley, G.L.; et al. The MIQE Guidelines: Minimum Information for Publication of Quantitative Real-Time PCR Experiments. Clin. Chem. 2009, 55, 611-622. [CrossRef] [PubMed]

39. Altincicek, B.; Knorr, E.; Vilcinskas, A. Beetle immunity: Identification of immune-inducible genes from the model insect Tribolium castaneum. Dev. Comp. Immunol. 2008, 32, 585-595. [CrossRef] [PubMed]

40. Arakane, Y.; Muthukrishnan, S.; Beeman, R.W.; Kanost, M.R.; Kramer, K.J. Laccase 2 is the phenoloxidase gene required for beetle cuticle tanning. Proc. Natl. Acad. Sci. USA 2005, 102, 11337-11342. [CrossRef] [PubMed]

41. Arakane, Y.; Dixit, R.; Begum, K.; Park, Y.; Specht, C.A.; Merzendorfer, H.; Kramer, K.J.; Muthukrishnan, S.; Beeman, R.W. Analysis of functions of the chitin deacetylase gene family in Tribolium castaneum. Insect Biochem. Mol. Biol. 2009, 39, 355-365. [CrossRef] [PubMed]

42. Contreras, E.; Rausell, C.; Real, M.D. Tribolium castaneum Apolipophorin-III acts as an immune response protein against Bacillus thuringiensis Cry3Ba toxic activity. J. Invertebr. Pathol. 2013, 113, 209-213. [CrossRef] [PubMed]

43. Li, J.; Lehmann, S.; Weißbecker, B.; Ojeda Naharros, I.; Schütz, S.; Joop, G.; Wimmer, E.A. Odoriferous Defensive stink gland transcriptome to identify novel genes necessary for quinone synthesis in the red flour beetle, Tribolium castaneum. PLoS Genet. 2013, 9, e1003596. [CrossRef] [PubMed]

44. Lord, J.C.; Hartzer, K.; Toutges, M.; Oppert, B. Evaluation of quantitative PCR reference genes for gene expression studies in Tribolium castaneum after fungal challenge. J. Microbiol. Methods 2010, 80, $219-221$. [CrossRef] [PubMed]

45. R Development Core Team. R: A Language and Environment for Statistical Computing; R Foundation for Statistical Computing: Vienna, Austria, 2008; ISBN 3-900051-07-0.

46. Therneau, T. A Package for Survival Analysis in S. R Package Version 2.37-4. Available online: https:// cran.rproject.org/web/packages/survival/index.html (accessed on 1 May 2016).

47. Matz, M.V.; Wright, R.M.; Scott, J.G. No Control Genes Required: Bayesian Analysis of qRT-PCR Data. PLoS ONE 2013, 8, e71448. [CrossRef] [PubMed]

48. Matz, M.V. MCMC.qpcr: Bayesian Analysis of qRT-PCR Data. 2016. Available online: https:// cran.r-project. org/web / packages/MCMC.qpcr/index.html (accessed on 14 November 2016).

49. Altincicek, B.; Elashry, A.; Guz, N.; Grundler, F.M.W.; Vilcinskas, A.; Dehne, H.-W. Next Generation Sequencing Based Transcriptome Analysis of Septic-Injury Responsive Genes in the Beetle Tribolium castaneum. PLoS ONE 2013, 8, e52004. [CrossRef] [PubMed]

50. Kim, Y.-S.; Ryu, J.-H.; Han, S.-J.; Choi, K.-H.; Nam, K.-B.; Jang, I.-H.; Lemaitre, B.; Brey, P.T.; Lee, W.-J. Gram-negative Bacteria-binding Protein, a Pattern Recognition Receptor for Lipopolysaccharide and $\beta-1,3-G l u c a n$ That Mediates the Signaling for the Induction of Innate Immune Genes in Drosophila melanogaster Cells. J. Biol. Chem. 2000, 275, 32721-32727. [CrossRef] [PubMed]

51. Gottar, M.; Gobert, V.; Michel, T.; Belvin, M.; Duyk, G.; Hoffmann, J.A.; Ferrandon, D.; Royet, J. The Drosophila immune response against Gram-negative bacteria is mediated by a peptidoglycan recognition protein. Nature 2002, 416, 640-644. [CrossRef] [PubMed]

52. Contreras, E.; Rausell, C.; Real, M.D. Proteome Response of Tribolium castaneum Larvae to Bacillus thuringiensis Toxin Producing Strains. PLoS ONE 2013, 8, e55330. [CrossRef]

53. Pekrul, S.; Grula, E.A. Mode of infection of the corn earworm (Heliothis zea) by Beauveria bassiana as revealed by scanning electron microscopy. J. Invertebr. Pathol. 1979, 34, 238-247. [CrossRef] 
54. Siebeneicher, S.R.; Bradleigh^Vinson, S.; Kenerley, C.M. Infection of the red imported fire ant by Beauveria bassiana through various routes of exposure. J. Invertebr. Pathol. 1992, 59, 280-285. [CrossRef]

55. Reber, A.; Chapuisat, M. No Evidence for Immune Priming in Ants Exposed to a Fungal Pathogen. PLoS ONE 2012, 7, e35372. [CrossRef] [PubMed]

56. Knorr, E.; Schmidtberg, H.; Arslan, D.; Bingsohn, L.; Vilcinskas, A. Translocation of bacteria from the gut to the eggs triggers maternal transgenerational immune priming in Tribolium castaneum. Biol. Lett. 2015, 11, 20150885. [CrossRef] [PubMed]

57. Bravo, A.; Gill, S.S.; Soberón, M. Mode of action of Bacillus thuringiensis Cry and Cyt toxins and their potential for insect control. Toxicon 2007, 49, 423-435. [CrossRef] [PubMed]

58. Pardo-López, L.; Soberón, M.; Bravo, A. Bacillus thuringiensis insecticidal three-domain Cry toxins: mode of action, insect resistance and consequences for crop protection. FEMS Microbiol. Rev. 2013, 37, 3-22. [CrossRef] [PubMed]

59. Rice, W.C.; Cogburn, R.R. Activity of the Entomopathogenic Fungus Beauveria bassiana (Deuteromycota: Hyphomycetes) Against Three Coleopteran Pests of Stored Grain. J. Econ. Entomol. 1999, 92, 691-694. [CrossRef]

60. Yanagita, T. Studies on oral infection of larvae of the silkworm, Bombyx mori, with Beauveria bassiana. J. Sericultural Sci. Jpn. 1987, 56, 279-284. [CrossRef]

61. Xiao, G.; Ying, S.-H.; Zheng, P.; Wang, Z.-L.; Zhang, S.; Xie, X.-Q.; Shang, Y.; St. Leger, R.J.; Zhao, G.-P.; Wang, C.; et al. Genomic perspectives on the evolution of fungal entomopathogenicity in Beauveria bassiana. Sci. Rep. 2012, 2. [CrossRef] [PubMed]

62. Kraaijeveld, A.R.; Godfray, H.C.J. Selection for resistance to a fungal pathogen in Drosophila melanogaster. Heredity 2008, 100, 400-406. [CrossRef] [PubMed]

63. Lacey, L.A.; Frutos, R.; Kaya, H.K.; Vail, P. Insect Phiathogens as Biological Control Agents: Do They Have a Future? Biol. Control 2001, 21, 230-248. [CrossRef]

64. Lacey, L.A.; Grzywacz, D.; Shapiro-Ilan, D.I.; Frutos, R.; Brownbridge, M.; Goettel, M.S. Insect pathogens as biological control agents: Back to the future. J. Invertebr. Pathol. 2015, 132, 1-41. [CrossRef] [PubMed]

65. Grau, T.; Vilcinskas, A.; Joop, G. Sustainable farming of the mealworm Tenebrio molitor for the production of food and feed. Z. Naturforschung C 2017, 72, 337-349. [CrossRef] [PubMed] 